\title{
SLAVIC PHRASEOLOGY FOR EXPRESSING VISUAL SEMANTICS
}

\author{
Iliana Genew-Puhalewa, Milena Hebal-Jezierska, JoAnNa BilińSKa \\ UNIVERSITY OF WARSAW \\ i.genew-puhalewa@uw.edu.pl,m.hebal-jezierska@uw.edu.pl,j.bilinska@uw.edu.pl
}

This paper presents an attempt to explore visual semantics (the semantic of seeing) in four Slavic languages: Bulgarian, Polish, Slovene and Czech. The theoretical apparatus of the study is based on the following concepts: Y. D. Apresyan's naive linguistic picture of man, A. Wierzbicka's semantic universals (including SEE) and I. Kasabov's view of phraseologisms as characterizing predicates and carriers of sign-lingual imagery. The approach adopted in the research is directed from meaning to form. Four main aspects of visual semantics have been identified and adequately described with relevant examples. The main conclusions of the study refer to: 1) the significant formal similarity between the four Slavic languages and 2) the necessity for direct naming of 'vision, seeing' (verb for 'seeing') or the 'eye' in the form of the phraseological units, a finding which confirms the hypothesis that SEE represents a fundamental concept.

Keywords: phraseology, semantics, comparative linguistics, semantic primitives, visual expression, seeing, eyes, Bulgarian, Polish, Slovene, Czech

\section{REFERENCES}

Apresian 1995: Apresian, J. D. Integral'noe opisanie iazyka i sistemnaia leksikografiia. Izbrannye trudy, t. 2. Moskva, Shkola „Iazyki russkoi kul'tury“.

AR 2016: Georgiev, M. (ed.), Mitologiya na choveshkoto tyalo. Antropologichen rechnik. Sofia, Izdatelstvo na BAN „Prof. Marin Drinov“.

Bartmiński 2014: Bartmiński, J. „Etnolingwistyka“ na jubileusz Profesor Anny Wierzbickiej“. - Etnolingwistyka, № 30. s. 21-44.

Bąba, Liberek 2002: Bąba, S., J. Liberek. Słownik frazeologiczny współczesnej polszczyzny. Warszawa, Wydawnictwo Naukowe PWN.

Genew-Puhalewa 2003: Genew-Puhalewa, I. Otsenachni frazeologichni edinitsi v balgarski, novogratski i polski ezik. Phd Thesis. Sofia.

Čermák 2009: Čermák, F. Slovník české frazeologie a idiomatiky. Praha.

Kaldieva-Zaharieva 2013: Kaldieva-Zaharieva, S. Balgarska leksikologiya i frazeologiya. T. 2. Balgarska frazeologiya. Sofia, Akademichno izdatelstvo „Prof. Marin Drinov“.

Kasabov 2013: Kasabov, I. Balgarska leksikologiya i frazeologiya. T. 3. Problemi na obshtata leksikologiya. Sofia, Akademichno izdatelstvo „Prof. Marin Drinov".

Keber 2015: Keber, J. Slovar slovenskih frazemov. Ljubljana. online: www.fran.si, 01.04.2019. 
Lakoff, Johnson 1980: Lakoff, G., M. Johnson. Metaphors We Live By. Chicago, University of Chicago Press.

Markou 2010: Markou, H. Metaforicheskoe pereosmyslenie glaz vo frazeologii russko-balkanskie lingvokul'turnye paralleli. - In: Materialy mezhdunarodnoi nauchno-prakticheskoi konferentsii. Moskva - Saloniki, s. 337-346.

Markou 2011: Markou, H. Frazeologichni edinitsi s komponent oko - ochi v balgarski i novogratski ezik - opit za sapostavitelen analiz. - Balkanite - ezik, istoriya, kultura, № 2, 406-416.

Mihaylova-Stalyanova 2011: Mihaylova-Stalyanova, $N$. Verba percipiendi v balgarski i polski ezik. Sofia, Universitetsko izdatelstvo „Sv. Kliment Ohridski“.

Nicheva 1993: Nicheva, K. Nov frazeologichen rechnik na balgarskiya ezik. Sofia, Universitetsko izdatelstvo „Sv. Kliment Ohridski“.

Nicheva, Spasova-Mihaylova, Cholakova 1974: Nicheva, K., S. Spasova-Mihaylo$v a, K$. Cholakova. Frazeologichen rechnik na balgarskiya ezik. Sofia, Izdatelstvo na BAN.

Orłoś, Hornik 1996: Orłoś, T. Z., J. Hornik. Czesko-polski słownik skrzydlatych słów. Kraków.

Pietrak-Meiser 1993: Pietrak-Meiser, H. Słownik frazeologiczny czesko-polski. Lublin.

San Roque, Kendrick, Niorcliffe, Majid 2018: San Roque, L., K. H. Kendrick, E. Niorcliffe, A. Majid. Universal meaning extensions of perception verbs are grounded in interaction. - Cognitive Linguistics, № 29 (3), p. 371-406.

SSJČ 1960-1971: Slovník spisovného jazyka českého, online: https://ssjc.ujc.cas. cz/search.php?db=ssjc, 04.04.2019.

SSKJ 2014: Slovar slovenskega knjižnega jezika, druga, dopolnjena in deloma prenovljena izdaja, online: www.fran.si, 02.04.2019.

Vaňková 2012: Vaňková, I. (ed.). Tělo, smysly, emoce v jazyce. Praha.

WSJP 2019: Wielki słownik języka polskiego, online: https://wsjp.pl, 05.04.2019.

Wierzbicka 1997: Wierzbicka, A. Understanding Cultures Through Their Key Words: English, Russian, Polish, German, and Japanese. Oxford University Press.

Wierzbicka 2008: Wierzbicka, A. Why There Are No 'Colour Universals' in Language and Thought. - The Journal of the Royal Anthropological Institute, Vol. 14, №2, s. 407-425.

Wierzbicka 2010: Wierzbicka, A. Semantyka. Jednostki elementarne i uniwersalne. Lublin, Wydawnictwo UMCS.

\author{
$\checkmark$ Iliana Genew-Puhalewa, Dr hab. \\ $\triangle$ Milena Hebal-Jezierska, PhD \\ $\triangle$ Joanna Bilińska, PhD \\ University of Warsaw \\ Institute of Western and Southern Slavic Studies \\ Krakowskie Przedmieście 26/28 \\ 00-927 Warszawa, Poland
}

